Received: 28-11-2018. Accepted: 13-01-2019. Published: 21-01-2019

\title{
Assessing the Roles of Network Structure and Social Media in Inter-units Knowledge Sharing \\ Djoko Sigit Sayogo ${ }^{1,2}$, Sri Budi Cantika Yuli ${ }^{1}$, Sri Wahyudi ${ }^{1}$, Wildan Affan ${ }^{1}$
}

\author{
Universitas Muhammadiyah Malang, Malang, Indonesia ${ }^{1}$ \\ Center for Technology in Government, Albany, New York, USA ${ }^{2}$
}

\begin{abstract}
Sharing knowledge across different units within an organization can be considered as one of the organization's fundamental operation. Nonetheless, sharing information and knowledge across boundaries presents tremendous challenges for organization. This paper discusses the impact of social network structure and social media in mediating knowledge sharing against unit task performance. Based on the review of extant literatures in intra-organization information and knowlegde sharing, this paper accentuates on three propositions as follows: a) the use of online collaborative media reduces time spend on task by accelerating the electronic document quality assurance process, $b$ ) integrating expert ability with the use of collaborative media reduces time spend on task by accelerating the electronic document quality assurance process, and c) social network structure increase the likelihood to extract personal advice from colleagues, thus improve unit's work quality.
\end{abstract}

Keywords: Knowledge sharing; intra-organization; social media; social network; network structure

\section{Introduction}

Social network analysis is regarded as useful tools to analyze information system practices (OinasKukkonen, Lyytinen, \& Yoo, 2010), in particular for clarifying the structure of knowledge management within organization or for managing and assessing strategic process of cooperation and improvement of collaboration within or across organization (Cross, Ehrlich, Dawson, \& Helferich, 2008; Cross, Parker, Prusak, \& Borgatti, 2001). Why, how, and when knowledge is shared among constituencies have been a widely investigated research area in various field of study such as organization, management, and communication (Brown \& Duguid, 2001; Haas \& Hansen, 2007; Hansen, 2002; Orlikowski, 2002). The ability of organization to shared knowledge among its constituencies has been considered as one of the most important competitive advantage (Haas \& Hansen, 2007; Watson \& Hewett, 2006). Leveraging on the significant role of knowledge in organization, scholars have been investigated the challenges of retaining and keeping knowledge within organizational boundaries (Brown \& Duguid, 2001) and sharing knowledge across organizational boundaries (Cross et al., 2001).

Integrating and bringing information and knowledge together across boundaries presents tremendous challenges, particularly relates to the differences in capabilities owned by each constituency (Pardo, Gil-Garcia, \& Burke, 2008). The degrees to which relationships among information users and other resources support collaboration and sharing - include staff, budget, training, and technology, and prior successes or failures in collaborative activities - affect the success of inter-organizational knowledge sharing (Pardo et al., 2005).

Challenges of knowledge sharing are also pertain internally within organization as well as externally among organizations. Sharing knowledge among units within organization entails costs and barriers. Lots of efforts, time, and money were spent by many knowledge intensive firms to obtain the benefits of better managing organizational knowledge (Watson \& Hewett, 2006). Each of organizational units differ in their internal knowledge, practices, and capabilities, result in different costs and barriers in searching and locating knowledge even within the boundary of organization (Tsai, 2001). Thus, "some business units are able to benefits from knowledge residing in other parts of organization while some don't" (Hansen, 2002). However, the relationship between knowledge sharing among organizational units on task performance improvement cannot yet be confirmed (Haas \& Hansen, 2005).

Haas \& Hansen (2007) study aim to address the above-mentioned issue by examining how task units use firm's knowledge resources to improve their performance. They proposed that different benefits can be derived from different types of knowledge by task units. Using two different construct of knowledge sharing - electronic documents and personal advice - they found that high quality of electronic document

\footnotetext{
1 dsayogo@umm.ac.id

2 dsayogo@ctg.albany.edu
} 
improve time saving yet has no significant effect on work quality or competent signaling, while personal advice improve work quality and competent signal but not saving time.

In their study, Haas \& Hansen (2007) was modeling their differentiated productivity of knowledge work by correlating knowledge sharing dimension directly to task performance ${ }^{3 .}$ This paper argues that directly relating knowledge sharing domain to task performance entails two caveats. First, although their model acknowledge social relation in the personal advice construct but they overlooks to incorporate the roles of network structure among units within organization in mediating the sharing of knowledge. Tsai (2001) found that network position has significant and positive impact on business unit innovation and performance (Tsai, 2001). Second, their model only considers information technology as tool to generate outcome (proxied as electronic document). In this regard, their model ignores the potential of information technology to mediate the process of sharing among units in organization. Physical proximity did assist in the transfer of knowledge due to the ability to convey trust (Leonard, 2007). However, the usefulness of physical distance becomes less clear with the use of information technology. People could send email to other person just two cubicles away in their office. The use of ICTs invokes the emergence perceived proximity, a feeling of closeness due to ICTs mediation although physically distance apart (Wilson, O'Leary, \& Jett, 2008). Thus, overlook to consider the role of ICTs in mediating the knowledge transfer process could undermine their model, more so with the rapid development of ICTs that support and facilitated interactivity such as social media.

Social media that emphasized on interactivity and multidirectional communication, users' generated content, and community based information diffusion has been prevalent (Wigand, 2010). Their unique and distinguishing feature is the ability to encourage interactivity and support for collaboration among users to share and generate knowledge within organization. Hence, this capabilities arguably could augment the effectiveness and productivity of knowledge sharing across different units within the organization (Wigand, 2010).

The purpose of this paper is in expanding Haas \& Hansen (2007) model by incorporating the impact of network structure and social media in mediating knowledge sharing against unit task performance. This paper addresses the following questions: does network structure mediate the impact of knowledge sharing on task performance among units in organization? To what extent does the use of social media affect the relations of knowledge sharing and task performance among units in organization? Do different technologies affect differently?

This paper is organized in five sections including the foregoing introduction. In the second section, this paper outlines the challenges in encouraging effective intra-organizational knowledge sharing. Subsequently, third section discusses the model integrating network structure and social media in mediating intra-organization knowlege sharing. Fourth section offers three propositions of the roles of network structure and social media in mediating the interactions in an intra-organizational knowledge sharing. Finally, section five presents the concluding remarks.

\section{Challenges of Intra-organizational Knowledge Sharing}

Research on knowledge sharing within and between organizations has been receiving vast attention from scholars (Argote, McEvily, \& Reagans, 2003). However, less attention has been dedicated to the intra-organizational knowledge sharing particularly related to the performance implication for task units within organization (Haas \& Hansen, 2007; Tsai, 2001, 2002).

Transfer of knowledge across different organizational units is considered as part of the learning process inside organization (Tsai, 2001). Inter unit relations help a project team search for useful knowledge in other subunits (Hansen, 1999), enables attainment of critical competencies through inter unit links (Tsai, 2001), and facilitate transfer of best practices among units within organization (Szulanski, 1996).

Nonetheless, transfer of knowledge among units within organizations are also impede with various challenges. These challenges represent the risks and costs of transferring knowledge across different units. The challenges of intra organizational knowledge transfer can be modeled based on Argote et.al. (2003) knowledge management contexts, namely: properties of units, properties of relations, and properties of knowledge.

The first challenge, the properties of units, refers to the characteristics of the unit in the organization. The characteristics of the unit are the key driver of effective knowledge management (Argote et al., 2003). Status of unit is one of the examples of unit attributes. The information and/or knowledge seeking behavior

\footnotetext{
${ }^{3}$ For the model, refers to Haas \& Hansen (2007) figure 1. a differentiated productivity model of knowledge work in page 1136.
} 
are contingent to the expertise, value, access, and cost of gaining the information and/or knowledge (Borgatti \& Cross, 2003). Individual will assess the expertise and evaluate the source quality in deciding where to seek advice, thus status is a prominent determinants in seeking knowledge (Borgatti \& Cross, 2003). Reputation for quality and focus developed by supplier significantly related to the perceived usefulness of information that they provided and complement the amount of information disclosed to their customer in competitive market (Hansen \& Haas, 2001).

The second challenge is the relational properties in knowledge sharing which signifies the relationships among units in organization (Argote et al., 2003). The stickiness of knowledge inside particular units Sulanzki (1996) can be regarded as one of the relational properties in knowledge sharing. Transferring best practices from one unit to another might be restricted by the inherent distinctive competence of particular units. Imitating best practice of one unit to another is made difficult due to the internal "stickiness" of transferring knowledge as a result of the differential in absorptive capacity among units, causal ambiguity, and inharmonious relations among units (Szulanski, 1996). The "stickiness" of knowledge transfer among units is also manifest in the structural embeddedness of relationship among organizational units (Tsai, 2001). Hansen (1999) findings demonstrate that different social ties create different facilitation of knowledge transfer among units. Weak ties are useful for searching useful knowledge from other units and strong ties are required for the transfer of complex knowledge (Hansen, 1999).

The last challenge involves the properties of knowledge itself. Knowledge transfer relate to the dichotomous properties of knowledge as tacit and explicit (Nonaka, 1994). The two dimensional of knowledge - tacit and explicit - create challenges in transferring knowledge since transferring explicit knowledge is less useful without tacit knowledge (Brown \& Duguid, 2001). Tacit knowledge is required to make explicit knowledge usable. Transferring and circulating explicit knowledge alone will affect the usefulness of the knowledge itself. Thus practice is the necessary tool to glue tacit and explicit knowledge(Brown \& Duguid, 2001). In addition, practice is in fact the necessary condition for transferring knowledge (Brown \& Duguid, 2001). Tacit is a form of knowing and thus inseparable from action since tacit is constructed through action (Orlikowski, 2002). Knowledge is created through everyday practice by constituting and reconstituting the ongoing social relations. Knowledge emerges at any given time subsequent to the practice that made it (Orlikowski, 2002).

Conclusively these challenges associated with knowledge management affect the process of sharing knowledge to enhance performance within inter or intra organization. Arguably overcoming challenges of knowledge sharing have to account for the relationship between properties of units, properties of relations, and inherent properties of knowledge itself.

\section{The Mediating Impact of Network Structure and Social Media: Remodeling the Productivity Model}

To address the challenges of knowledge sharing across units and the relationship of knowledge sharing to the unit's task performance in organization, this paper remodeled the "Differentiated Productivity Model of Knowledge Work" proposed by Hass and Hansen (2007) ${ }^{4}$. This paper argue that network structure and social media mediate the impact of knowledge sharing to unit task performance. Thus, the proposed remodel framework consist of two types of knowledge sharing - electronic document and personal advice, the mediating variables - network structure and Social Media, and two primary unit task performance outcomes (refers to figure 1).

\footnotetext{
${ }^{4}$ For the original model, refers to Haas \& Hansen (2007) figure 1. a differentiated productivity model of knowledge work in page 1136.
} 


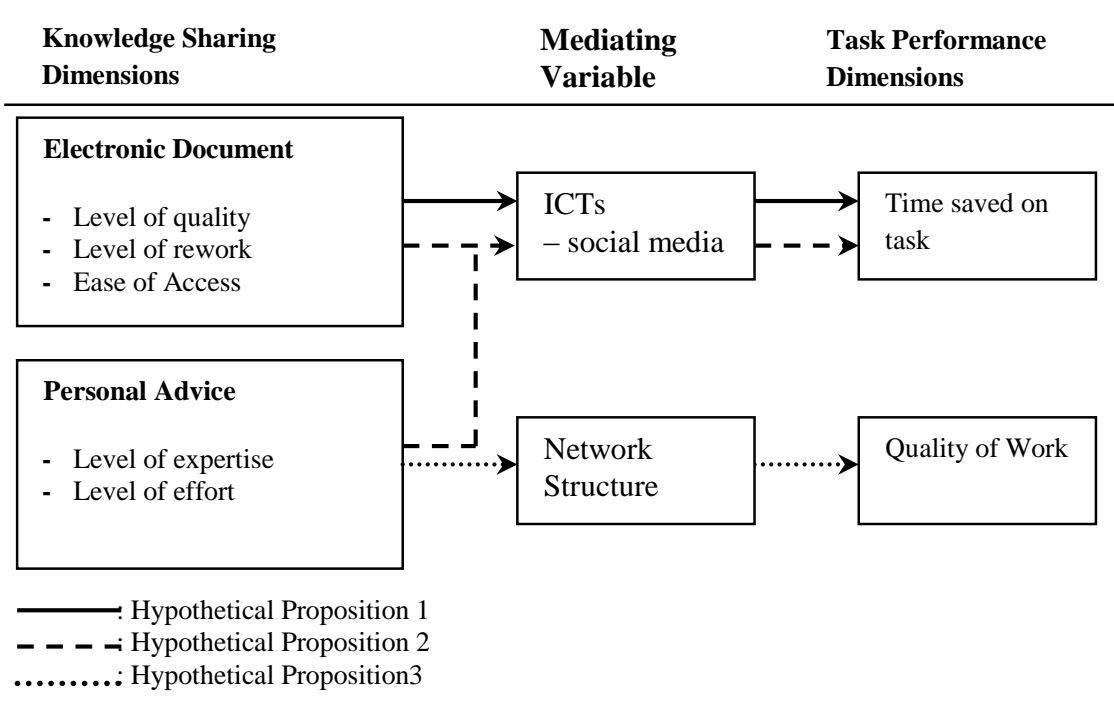

Source: Adapted from Haas \& Hansen (2007),

Figure 1. The Extended Model of "Productivity Model of Knowledge Work"

Two types of knowledge sharing consist of electronic document and personal advice. Haas \& Hansen (2007) proposed that transferring of knowledge across different units is possible through two distinct means, namely direct contact between individuals and/or written documents in electronic format. Interpersonal relations and social cohesion will influence the extent of knowledge sharing among individuals (Casciaro \& Lobo, 2005; Reagans \& McEvily, 2003). Cohesive network and relationship will influence the degree of investment of resource to support the effort of knowledge sharing (Reagans \& McEvily, 2003). Individual will choose with whom they would like to work with and partner selection affect the performance of knowledge transfer (Casciaro \& Lobo, 2005). On the other hand, sharing of knowledge could also occur indirectly through written document. In this instance, the relationship is indirect in which individual records what they know and archived it into database that other individuals will retrieve when needed.

However, the usefulness of knowledge derived from other units either through electronic documents or personal advices entail values, costs, and efforts (Borgatti \& Cross, 2003; Haas \& Hansen, 2007). The units seek for information and derived information from electronic archive need to assess the quality of the documents to understand the potential values of using the knowledge entail within the documents (Haas \& Hansen, 2007). The unit seeking for knowledge might need to assess the quality, rework the document, and/or hamper by access restriction that might potentially reduce the usefulness of the knowledge for the specified task and affect the performance of particular task. Restrictions to access impersonal sources such as written document - hamper the motivation of individuals in using the sources (O'Reilly, 1982).

Nonetheless, the processes of assuring the quality of document, the extent level of rework, and increase ease of access can be promoted by the use of social media technologies such as: wikis, blogs, and/or sharepoints. Social media for collaborative and knowledge sharing purposes have been increasingly adopted by many organizations (Boulos, Maramba, \& Wheeler, 2006; Matuszak, 2007). The social media, particularly the collaborativeware such as wikis and blogs, provides opportunity for information sharing and ease of collaboration (Boulos et al., 2006). Social media can be useful source for obtaining information, sharing dialogue and knowledge among project participants, or allowing for collaborative learning process (Boulos et al., 2006). The ability of social media in facilitating collaborative space for sharing what the individuals know, link to external content, and summarizing comments on particular issue (Fichter, 2005) could accelerate the process of quality assurance of the electronic documents.

Using the above-mentioned logic, arguably requesting advice from coworkers in other units might entail costs and efforts. Individuals have to search and choose with whom they should seek advice. Individuals are more willing and motivated to invest time, energy, and effort in seeking for knowledge sharing with others who have expertise (Borgatti \& Cross, 2003). In addition, individual will tend to seek for knowledge in which he/she positively evaluate other's knowledge and skills in the domain relevant to his or her work (Borgatti \& Cross, 2003). On the other hand, the level of expertise is also needed not only for the advisors but also for the advisee for assessing the usefulness of particular knowledge derived from other's advice (Haas \& Hansen, 2007). 
The efforts and costs associated with searching for personal advice is mediated by the structural relationship within the organization. Szulanski (1996) argued that arduous relations among units might inhibit sharing of knowledge. The culture of organization that inhibits sharing will affect the likelihood of units to share their information and knowledge. Similarly, sharing knowledge among individuals also affected by the extent whether the individuals are likeable since likeable persons are more likely to encourage sharing (Casciaro \& Lobo, 2005). In addition, the network structure such as central network position significantly correlate to access on useful knowledge from other units as compare to units in periphery position (Tsai, 2001).

Haas \& Hansen (2007) proposing three task performance dimensions that are prominent for interunits knowledge sharing, namely saving time, quality of work, and signal of competence (Haas \& Hansen, 2007). The object of Haas and Hansen (2007) research is knowledge sharing for developing sales proposal. Thus logically in addition to the time saving and quality of work, conveying signal of competence to the customer is one of crucial determinants of success. Haas (2006) argues that the benefits of knowledge gathering depend on contextual elements, such as ambiguity of task and politics. Thus, different environmental context or object of research might entail the need of different constructs (Haas, 2006). In this extended model, only time saving and quality of work are considered. Subsequently, this paper suggest three propositions related to the roles of social network structure and social media in intra-organizational knowledge sharing in the subsequent section.

\section{The Roles of Network Structure and Social Media: The Proposition Social Media as Mediator and Time Saving}

Time saving on task completion has been regarded as the primary benefit of knowledge sharing (Marks, Polak, McCoy, \& Galletta, 2008; Ruuska \& Vartiainen, 2005; Voelpel \& Han, 2005). The sharing of knowledge across units and individuals within organization could save considerable time for the knowledge receiver and providers (Marks et al., 2008; Voelpel \& Han, 2005). One of the time saving mechanism is through the reduction in time for searching and finding information (Ruuska \& Vartiainen, 2005). Another mechanism facilitate in reducing time for task completion is through avoiding redundant effort in analyzing information / facts / knowledge already analyzed by other units. Electronic documents are usually supported with detailed information and well-developed analysis (Haas \& Hansen, 2007). Thus, using electronic documents will prevent units to perform redundant efforts already done by others.

Nevertheless, the ability of electronic document to speed up the task completion process also depends on the usefulness of the documents, namely: the quality of work, amount of needed reworks (Haas \& Hansen, 2007), and ease in accessing the document. Thus, using electronic document for proxy of knowledge requires "assurance process", a process to assure that the quality of document meet the expectation of the unit seeking knowledge or information. This assurance processes could be counterproductive. Although information is available electronically, the seeking units might have to invest additional time and efforts if the qualities of documents are questionable or not fit with the seeking units' need that will result in adding time in completing the tasks.

The use of social media - particularly the collaborative ware such as wikis and blogs - could promote and accelerate the process in "assuring" the quality of the document, reducing the amount of necessary rework, and increase ease of access. Majcharzak et.al. (2000) argued that critical to the usefulness of ICTs in facilitating collaboration is not just as mechanism for exchanging information, but should also entails the mechanism for creating a knowledge repository and for accessing knowledge repository in which technology such as email fail to accomplished (Majchrzak, Rice, King, Malhotra, \& Ba, 2000). Social media provide useful platform for collaborative discovery and virtual work space for sharing what the individuals know, link to external content, and summarizing comments on particular issue (Fichter, 2005). The social media can be useful source for obtaining information, sharing dialogue and knowledge among project participants, or allowing for collaborative learning process (Boulos et al., 2006).

"Two heads are better than one" as an old wisdom and axiom is put in more grand scale through the use of collaborative ware (Matuszak, 2007). Various heads can work simultaneously using social media as collaborative tools to reduce time needed for assuring document quality and level of reworks. Social media extends the ability to harness brainpower outside the units, facilitate brainstorming electronically without having to set up time consuming physical meetings.

Various success stories accentuates the ability of social media in encouraging interactive dialogue and active learning, or assist the construction of shared knowledge (Boulos et al., 2006). Intellipedia, a system that uses the same software as the publicWikipedia, is proving to be a successful means for intelligence officers to share ideas and solve problems (Beizer, 2008). Intellipedia allow interested 
individuals with even little time to contribute and help analyze security threats that would have been excluded due to geographic boundaries (Matuszak, 2007). Dell uses a blog - Direct2Dell ${ }^{5}$ - to link those who need answers to experts and IBM operates dozens of wikis (such as the Community Patent) to use "the wisdom of crowds" to help review patent applications (Matuszak, 2007).

Conclusively, online collaborative tools provide affordances to mediate the knowledge sharing through electronic document to reduce time for task completion. The social media have potentials to reduce the time needed to assure the quality of documents used and the level of reworks needed. In addition, social media ability to link experts to those who need answer integrate the use of electronic documents and experts' advice in knowledge sharing domains to accelerate time needed to complete tasks.

Proposition 1: The use of online collaborative media reduces time spend on task by accelerating the electronic document quality assurance process

Proposition 2: Integrating expert ability with the use of collaborative media reduces time spend on task by accelerating the electronic document quality assurance process

\section{Personal Advice, Network Structure and Improvement of Quality of Work}

Some tasks are more suited to be accomplished using direct personal contact due to its ambiguity (Majchrzak et al., 2000). Direct contact enables richer cues and removal of anonymity, which in turn provide more information for evaluating trustworthiness in collaboration (Brochet, Page, \& Putterman, 2006; Frohlich \& Oppenheimer, 1998). Tapping experience colleagues was synonymously related to higher source of quality of knowledge as compare to documentations (O'Reilly, 1982). Task's unit can benefits from high-quality inputs from their experienced colleagues to improve their work quality (Haas \& Hansen, 2007). The benefits of personal advice is not only related to the richness of direct personal contact but experienced colleagues - assume to have more local knowledge context - could assist in customizing and tailoring the knowledge to fit with need of particular unit (Haas \& Hansen, 2007).

On the other hand, the above-mentioned assertion is based on the assumption that experienced colleagues will be voluntarily and willingly invest their time and efforts to help the needed units. In the organization, some colleagues might have high experience and expertise but really difficult to work with (Casciaro \& Lobo, 2005) or less willing to invest their effort. The lack of effort of experienced colleagues to assist and share knowledge will have significantly negative correlation with the quality of work.

Arguably, the effort and cost associated with searching, initiating, and managing direct personal advice is mediated by the structural relationship within organization. Arduous relationship among units in the organization could hamper knowledge sharing and impose stickiness of knowledge on particular unit (Szulanski, 1996). Loveable persons will receive more information or knowledge whether they want it or not and competent jerks are avoided (Casciaro \& Lobo, 2005).

Conclusively, the structure of network could influence the degree of involvement and willingness of experienced colleagues to assist and engage in knowledge sharing among units in organization. The tension between power, control, and interdependencies among organizations create various possible structures (Aldrich \& Pfeffer, 1976). Different opportunities is associated with different positions in the network since different positions is related to different resources and power (Tsai, 2001). Two network structures are discussed in this research, namely: network centrality and structural equivalence.

Centrality refers to the strategic positions of actors within particular network. Actors with central position in the network are more likely to attained more power (Brass, Galaskiewicz, Greve, \& Tsai, 2004) and have greater access to resources and information (Brass et al., 2004; Gnyawali \& Madhavan, 2001). Actors in the central position will become the first one to recognize the emergence of new innovation (Abrahamson \& Rosenkopf, 1997) and possible usefulness to its unit. Due to the power and knowledge held by central actors in the network, associating with central actors will be advantageous. As result, central network position significantly correlates to access on useful knowledge from other units as compare to units in periphery position (Tsai, 2001). Thus, presumably, experienced colleagues are keen and more willing to associate themselves and share knowledge with others who have central position as compare to those who have periphery position.

However, centrality was not the only stimulus of knowledge sharing. Actors have higher likelihood to interact with other who is perceived to have similar roles. The similarity in the relationship patterns and roles is regarded as structural equivalence (Wasserman \& Faust, 1994). Gnyawali and Madhavan (2001) argued that actors more likely to have similar behavior if they are structurally equivalent. In addition, structurally equivalent actors are more likely to mimics and imitate each other to gain social legitimacy

\footnotetext{
${ }^{5}$ For more information refers to http://en.community.dell.com/dell-blogs/Direct2Dell/b/direct2dell/default.aspx
} 
(Gnyawali \& Madhavan, 2001). Presumably, experienced colleagues are more likely and more willing to provide advice to other units who are structurally equivalence with them.

Proposition 3: Network structure increase the likelihood to extract personal advice from colleagues, thus improve unit's work quality

\section{Concluding Remarks}

This paper contributes in expanding the extant literature on inter-unit knowledge sharing by arguing and proposing the importance of understanding the roles of network structure and social media in mediating the sharing across different units. While acknowledging the necessity of personal advice relations in achieving effective knowledge sharing, this study expands such notion by arguing that the effectiveness of personal advice is contigent to the structural relationships among the individuals in the unit. Through informal relationships, individuals formed social network structure in the organization which mediate the effectiveness of sharing relationships. Subsequently, studies on intra-unit knowledge sharing, such as Haas \& Hansen (2007) simplified the roles of information and communication technologies (ICTs) as a tool to generate outcome in the sharing relationships. Such argumentation fails to consider the potentials of ICTs, particularly social media, as interactive tools to mediate and accelerate the sharing relationship among the units.

This paper thus expands the scholarship on intra-organization knowledge sharing by conceptually suggesting three propositions in relation to the roles of network structure and social media in inter-units sharing within an organization. This paper argues that the use of social media - particularly the collaborative ware such as wikis and blogs - could promote and accelerate the process in "assuring" the quality of the document, reducing the amount of necessary rework, and increase ease of access in the intra-organization knowledge sharing. online collaborative tools provide affordances to mediate the knowledge sharing through electronic document to reduce time for task completion. The social media have potentials to reduce the time needed to assure the quality of documents used and the level of reworks needed. In addition, social media ability to link experts to those who need answer integrate the use of electronic documents and experts' advice in knowledge sharing domains to accelerate time needed to complete tasks. As such, this paper accentuates on two propositions as follows: a) the use of online collaborative media reduces time spend on task by accelerating the electronic document quality assurance process and $b$ ) integrating expert ability with the use of collaborative media reduces time spend on task by accelerating the electronic document quality assurance process.

Subsequently, individuals in organization develop informal relations overtime which then cemented into personal network structure. Thus, this network structure arguably influence the degree of involvement and willingness of colleagues to assist and engage in knowledge sharing among units in organization. Likewise, different opportunities is associated with different positions in the network since different positions is related to different resources and power. Hence, this paper proposes that social network structure increase the likelihood to extract personal advice from colleagues, thus improve unit's work quality.

\section{References}

Abrahamson, E., \& Rosenkopf, L. (1997). Social Network Effects on the Extent of Innovation Diffusion: a Computer Simulation. Organization Science, 8(3), 289.

Aldrich, H. E., \& Pfeffer, J. (1976). Environments of Organizations. Annual Review of Sociology, 2, 79105.

Argote, L., McEvily, B., \& Reagans, R. (2003). Managing Knowledge in Organizations: an Integrative Framework and Review of Emerging Themes. Management Science, 49(4), 571-582.

Beizer, D. (2008). a Key to Understanding Data [Electronic Version]. Washington Technology, 23, 30-31. Retrieved 12/12/2010,

Borgatti, S. P., \& Cross, R. (2003). A Relational View of Information Seeking and Learning in Social Networks. Management Science, 49(4), 432-445.

Boulos, M. N. K., Maramba, I., \& Wheeler, S. (2006). Wikis, Blogs, and Podcasts: a New Generation of Web-based Tools for Virtual Collaborative Clinical Practice and Education. BMC Medical Education, 6:41.

Brass, D., Galaskiewicz, J., Greve, H. R., \& Tsai, W. (2004). Taking Stock of Networks and Organizations: a Multilevel Perspective. Academy of Management Journal, 47, 795-817. 
Brochet, O., Page, T., \& Putterman, L. (2006). Communication and Punishment in Voluntary Contribution Experiments. Journal of Economic Behavior \& Organization, 60, 11-26.

Brown, J. S., \& Duguid, P. (2001). Knowledge and Organization: a Social-Practice Perspective. Organization Science, 12(2), 198-213.

Casciaro, T., \& Lobo, M. S. (2005). Competent Jerks, Lovable Fools, and the Formation of Social Networks. Harvard Business Review, 83(6), 92-99.

Cross, R., Ehrlich, K., Dawson, R., \& Helferich, J. (2008). Managing Collaboration: Improving Team Effectiveness Through a Network Perspective. California Management Review, 50(4), 74-98.

Cross, R., Parker, A., Prusak, L., \& Borgatti, S. P. (2001). Knowing What We Know: Supporting Knowledge Creation and Sharing in Social Network. Organizational Dynamics, 30(2), 100-120.

Fichter, D. (2005). Intranets, Wikis, Blikis, and Collaborative Working [Electronic Version]. ONLINE,

Frohlich, N., \& Oppenheimer, J. (1998). Some Consequences of e-mail vs. face to face Communication in Experiment. Journal of Economic Behavior \& Organization, 35, 389-403.

Gnyawali, D. R., \& Madhavan, R. (2001). Cooperative Networks and Competitive Dynamics: a Structural Embeddedness Perspective. Academy of Management Review, 26(3), 431-445.

Haas, M. R. (2006). Knowledge Gathering, Team Capabilities, and Project Performance in Challenging Work Environment. Management Science, 52(8), 1170-1184.

Haas, M. R., \& Hansen, M. T. (2005). When Using Knowledge Can Hurt Performance: the Value of Organizational Capabilities in a Management Consulting Company. Strategic Management Journal, 26(1), 1-24.

Haas, M. R., \& Hansen, M. T. (2007). Different Knowledge, Different Benefits: Toward a Productivity Perspective on Knowledge Sharing in Organizations. Strategic Management Journal, 28, 11331153.

Hansen, M. T. (1999). The Search-Transfer Problem: The Role of Weak Ties in Sharing Knowledge Across Organization Subunits. Administrative Science Quarterly, 44(1), 82-111.

Hansen, M. T. (2002). Knowledge Networks: Explaining Effective Knowledge Sharing in Multiunit Companies. Organization Science, 13(3), 232-248.

Hansen, M. T., \& Haas, M. R. (2001). Competing for Attention in Knowledge Markets: Electronic Document Dissemination in a Management Consulting Company. Administrative Science Quarterly, 46(1), 1-28.

Leonard, D. (2007). Knowledge Transfer within Organization. In K. Ichijo \& I. Nonaka (Eds.), Knowledge Creation and Management: New Challenges for Managers. New York: Oxford University of Press.

Majchrzak, A., Rice, R. E., King, N., Malhotra, A., \& Ba, S. (2000). Computer-Mediated InterOrganizational Knowledge-Sharing: Insights from a Virtual Team Innovating Using a Collaborative Tool. Information Resource Management Journal, 13(1), 44-53.

Marks, P., Polak, P., McCoy, S., \& Galletta, D. (2008). Sharing Knowledge. Communications of the ACM, 51(2), 60-65.

Matuszak, G. (2007). Enterprise 2.0: Fad or Future? The Business Role for Social Software Platforms: KPMGo. Document Number)

Nonaka, I. (1994). A Dynamic Theory of Organizational Knowledge Creation. Organization Science, 5(1), 14-37.

O'Reilly, C. A. (1982). Variations in Decision Makers' Use of Information Sources: The Impact of Quality and Accessibility of Information. Academy of Management Journal, 25 (4), 756-771.

Oinas-Kukkonen, H., Lyytinen, K., \& Yoo, Y. (2010). Social Networks and Information Systems: Ongoing and Future Research Streams. Journal of the Association for Information Systems (JAIS), 11(special issue), 61-68.

Orlikowski, W. J. (2002). Knowing in Practice: Enacting a Collective Capability in Distributed Organizing. Organization Science, 13(3), 249-273.

Pardo, T. A., Cresswell, A. M., Dawes, S. S., Burke, G. B., Dadayan, L., \& Embar, S. (2005). Building State Government Digital Preservation Partnerships: a Capability Assessment and Planning Toolkit. Albany, NY: Center for Technology in Governmento. Document Number)

Pardo, T. A., Gil-Garcia, R. J., \& Burke, G. B. (2008). Sustainable Cross-Boundary Information Sharing. In H. Chen, L. Brandt, S. S. Dawes, V. Gregg, E. Hovy, A. Macintosh, R. Trunmuller \& C. A. Larson (Eds.), Digital Government: Advanced Research and Case Studies (pp. 423-440). New York: Springer.

Reagans, R., \& McEvily, B. (2003). Network Structure and Knowledge Transfer: The Effects of Cohesion and Range. Administrative Science Quarterly, 48(2), 240-267. 
Ruuska, I., \& Vartiainen, M. (2005). Characteristics of Knowledge Sharing Communities in Project Organizations. International Journal of Project Management, 23, 374-379.

Szulanski, G. (1996). Exploring Internal Stickiness: Impediments to the Transfer of Best Practice Within the Firm. Strategic Management Journal, 17(Winter special issue), 27-43.

Tsai, W. (2001). Knowledge Transfer in Intraorganizational Networks: Effects of Network Position and Absorptive Capacity on Business Unit Innovation and Performance. Academy of Management Journal, 44(5), 996-1004.

Tsai, W. (2002). Social Structure of "Coopetition" Within a Multiunit Organization: Coordination, Competition, and Intraorganizational Knowledge Sharing. Organization Science, 13(2), 179-190.

Voelpel, S. C., \& Han, Z. (2005). Managing Knowledge Sharing in China: the Case of Siemens ShareNet. Journal of Knowledge Management, 9(3), 51-63.

Wasserman, S., \& Faust, K. (1994). Social Network Analysis: Methods and Applications.

Watson, S., \& Hewett, K. (2006). A Multi-Theoretical Model of Knowledge Transfer in Organizations: Determinants of Knowledge Contribution and Knowledge Reuse. Journal of Management Studies, 43(2), 142-173.

Wigand, F. D. L. (2010). Adoption of Web 2.0 by Canadian and US Government. In C. G. Reddick (Ed.), Comparative E-Government (pp. 161-181). New York: Springer-Verlag.

Wilson, J.M., O'Leary, M.B., Metiu, A., \& Jett, Q.R. (2008), Perceived Proximity in Virtual Work: Explaining the Paradox of Far-but-close, Organization Studies, 29(7), 979-1002. 
Assessing The Role of Network Structure and Social Media ... (Sayogo, Yuli, Wahyudi, Affan) 